\title{
Diabetic Gastrointestinal Neuropathy: Elusive Diagnosis and Difficult Treatment
}

\author{
Patrizio Tatti ${ }^{*}, 1$, Felice Strollo ${ }^{2}$ and Annabel Barber ${ }^{3}$ \\ ${ }^{I}$ Endocrinology and Diabetes Unit-ASL RMH, Roma, Italy \\ ${ }^{2}$ Istituto INRCA, Roma, Italy \\ ${ }^{3}$ University of Nevada, Las Vegas, USA
}

\begin{abstract}
Diabetic Gastrointestinal Neuropathy is an elusive diagnosis and often overlooked. The affected patients do not connect the symptoms with diabetes and undergo a painstaking and expensive search for other disorders of the digestive tract. Diabetic Gastrointestinal Neuropathy additionally causes a baffling glucose instability that further aggravates the condition. The treatment is difficult. The less severe cases respond to prokinetic treatment, but when the disease is advanced the only available therapy is the insertion of a pacemaker.
\end{abstract}

Keywords: Diabetic gastrointestinal neuropathy, glucose variability, gastrointestinal pacemaker.

\section{INTRODUCTION}

Diabetic gastrointestinal neuropathy is a frequent condition present in nearly $50 \%$ of the diabetic population [1] both type $1[1,2]$ and type 2 [3], but unfortunately, rarely recognized. The medical literature on this topic is rather limited. A search of PubliMed for the term "diabetic Gastroparesis" returned 587 papers, with 125 being reviews. The affected patients do not connect the symptoms with diabetes and undergo a painstaking and expensive search for other disorders of the digestive tract. Diabetic Gastrointestinal Neuropathy also causes a baffling glucose instability that further aggravates the condition. The treatment is difficult. The less severe cases respond to prokinetic treatment, but when the disease is advanced the only available treatment is the insertion of a pacemaker.

\section{PATHOPHYSIOLOGY AND SYMPTOMS}

The signs and symptoms vary from the full blown picture that clinches the diagnosis to the most elusive one. Esophageal dysfunction may cause heartburn, anol reflux, dysphagia. The gastric involvement may impair gastric acid secretion and interfere with the motility to the extreme degrees of gastroparesis diabeticorum. Among the symptoms are early satiety, nausea, anorexia, vomiting, epigastric discomfort and bloating which are easily dismissed or attributed to drugs. In this condition there may be emesis of undigested food. Most commonly extreme irregularity and unpredictable fluctuations of the blood glucose [4] due to the erratic absorption of food may appear. In the extreme states the life of the patient is miserable with wasting and loss of weight. Often the symptoms are elusive and the outstanding manifestation is a mindboggling glucose instability with unexpected peaks at any time of the day and unexplained

*Address correspondence to this author at the Diabetes and Endocrinology Unit - ASL RMH, Italy; Tel:+390693273094; Fax:+39063218855;

E-mails: info@patriziotatti.it, tatti0@tin.it and unpredictable hypoglycemic episodes that impact on the life of the patient and his family [5]. Hypoglycemia is a serious limiting factor for the intensive treatment of hyperglycemia at any age [6, 7]. Beyond its ravaging consequences GI neuropathy may be a marker of other neuropathies and diabetic complications. Furthermore, the frequent vomiting causes alteration in absorption of nutrients and additional damage to the body. Recent data suggest that a delayed radionucleotide gastric emptying study predicts increased mortality in diabetic patients with symptoms of gastroparesis, [8] irrespective of the cardiovascular involvement [9].

Diabetic gastropathy is a heterogenous syndrome, and the diagnosis is not straightforward. The term should probably be revisited [10]. The emptying of liquids behaves unpredictably [11-13] and the ingestion of solid meals appears to be more consistently delayed [14] with retention in the proximal stomach [15]. There is no Gold Standard for the diagnosis, and this has hampered the definitive evaluation of the impact of this complication and its treatment. Another complicating factor is the behavior of the gastric motility according to the blood glucose level. In healthy subjects the rate of gastric emptying is slower during experimental hyperglycemia [16-18]; the reverse is also true because in the experimental setting in type 1 diabetics solid and liquid foods are apparently absorbed more rapidly during hypoglycemia [19]. While this behavior is entirely consistent with an attempt to modulate the blood glucose level, all these data were obtained in different populations and under different conditions and should be replicated with the actual technology. Moreover it is yet to be demonstrated that these responses obtained in an acute setting hold true also in the chronic state, since the limited data we have argue against this mechanism [20,21]. It is not known if and to what degree autonomic neuropathy may interfere with these processes. The knowledge of these mechanisms and their derangements is of the outmost relevance to the treatment of diabetes mellitus because a correct match between food 

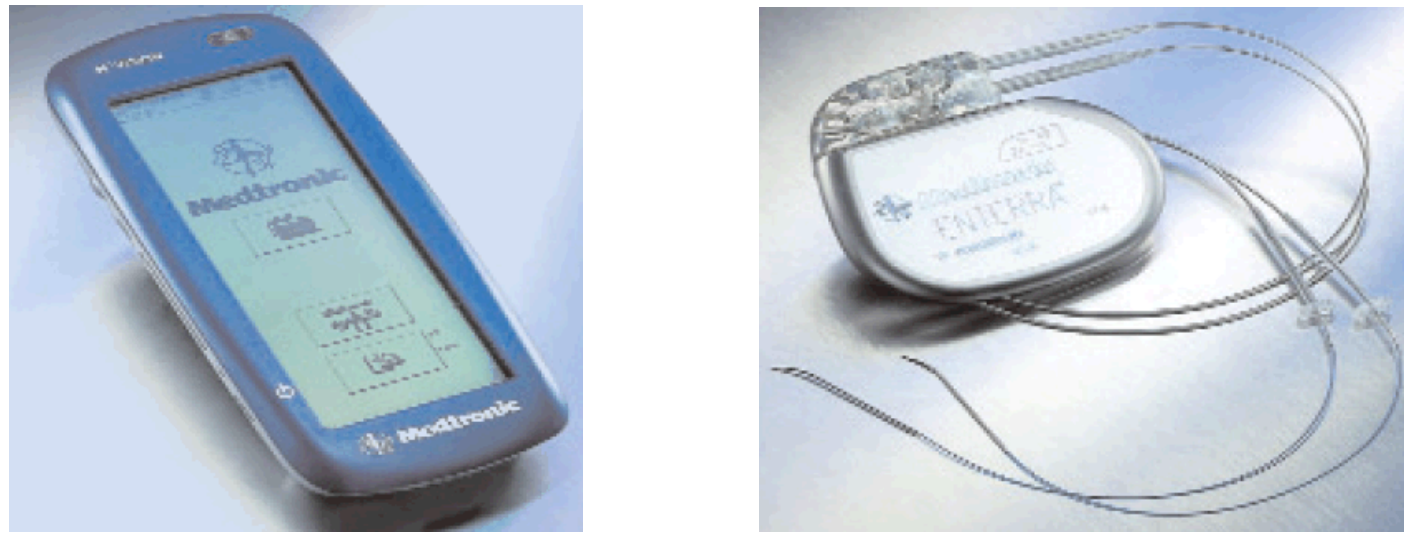

Fig. (1). The device in its typical presentation (courtesy of Medtronic Inc).

absorption and insulin or oral euglycemic agents has a key role in maintaining a normal blood glucose level. Another key aspect not solved is the role of the nutrients in modulating the intestinal motility which could concur to determine the characteristic glycemic response to food we know as the glycemic index.

It is also possible that gastric neuropathy is due to an intestinal myopathy possibly associated to the dysfunction of the local nerve plexus, although this is based on conflicting results $[22,23]$. In summary, many factors influence the gastric emptying, the most prominent being loss of the interstitial pacemaker cells of Cajal, disturbed neurotransmission and altered hormonal environment [24].

\section{MEDICAL TREATMENT AND GASTRIC ELECTRIC STIMULATION}

The first line treatment for gastroparesis is made of prokinetics and antiemetic drugs. The former ones are metoclopramide, which is endowed with CNS side effects as dosage increases, and domperidone. Erythromycin also belongs to this category but usually induces tachyphylaxis leading to its abandonment. Antiemetics include phenothiazines, antihistamines and serotonin antagonists, and can be given alone, but often are added to prokinetics. All of these drugs are used empirically and are not expected to be highly effective. In alternative low-dose tricyclic antidepressants can be used when nothing helps. Even pyloric injections of botulinum toxin may be chosen to induce muscle paralysis and pylorospasm relief in extremely refractory cases, but their usefulness is debatable [25-28].

The introduction of Prucalopride [29], a new, selective 5HT (4) agonist and enterokinetic, for the treatment of constipation in women elicited some hopes, but there are at present no data on its efficacy.

When no medical treatment strategy helps Gastric Electric Stimulation (GES) may be attempted. This technique makes use of an implantable stimulator, like the Enterra ${ }^{\circledR}$ Therapy, Medtronic Inc., MN, USA, which has been approved by the US FDA for the treatment of severe and refractory gastroparesis (Figs. 1, 2). High frequency GES delivers a high-frequency $(12 \mathrm{cpm})$, low-energy signal in short pulses and must be distinguished from "gastric pacing" that delivers high-energy stimuli at a frequency slightly above that of the intrinsic slow wave activity. The higher-frequency stimulus does not entrain slow waves or reverse underlying slow wave dysrhythmias. Stimulating wires attached to the electric stimulator - which is positioned in a subcutaneous abdominal pouch - are sutured into the gastric muscle along the greater curvature during laparoscopy or laparotomy. This procedure is expected to nearly normalize stomach motility and relieve patients' symptoms. Its effects seem to be promising as successful results have been reported in as many as $50 \%$ to $80 \%$ cases, although the ability to promote gastric emptying through enhanced motility was relatively low. An explanation may be that gastric stimulation of vagal afferents may be able to suppress the vomiting centers in the brain [27, 30-32].

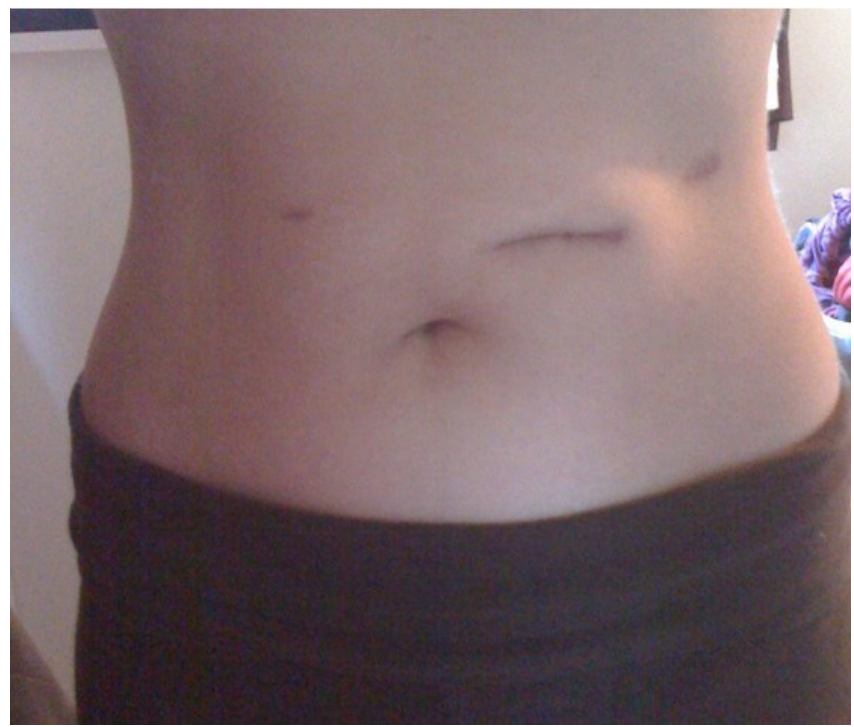

Fig. (2). Site of insertion of Enterra.

According to a review published by the American Gastroenterological Association (AGA) in 2004 GES is an emerging treatment for diabetic refractory gastroparesis which seems to promote gastric emptying of liquids better than of solids. In long-term follow-up this tool yielded a reduction in the mean vomiting frequency from 25 to 6 times per week with an associated improvement in quality of life, improved nutritional parameters and decreased requirements for supplemental feedings [33]. Unfortunately some openlabel studies have not confirmed this benefit [34]. Because of potential advantages the gastric electric neurostimulator was granted humanitarian approval from the FDA for the 
treatment of chronic, refractory nausea and vomiting secondary to idiopathic or diabetic gastroparesis. Some complications have been reported, mainly infections necessitating device removal in approximately $5 \%-10 \%$ of cases. According to the AGA further investigation is needed to confirm the effectiveness of gastric stimulation in long term blinded studies. The key questions needing answer are which patients are likely to respond, the optimal electrode placement, and the optimal stimulation parameters, none of which had been rigorously evaluated (American Gastroenterological Association Technical Review on the Diagnosis and Treatment of Gastroparesis) [35] and still have not been so far.

This is the reason why other experiments have been performed during the last few years, including the one by Lin's group [36] who retrospectively reviewed all patients undergoing GES implantation at the University of Kansas Medical Center (KUMC) from 1998 to 2002, to analyze the effects of GES on symptoms, health-related quality of life (HQOL), nutritional status, GE, and the degree of glucose control in 48 diabetic patients who had medically refractory gastroparesis and at least 12 months of follow-up available. In agreement with previous studies on GES in gastroparesis [37-40] they confirmed that GES by a permanently implantable system (Enterra Therapy) significantly reduced severity and frequency of all upper GI symptoms assessed, including vomiting, nausea, early satiety, bloating, postprandial fullness, and epigastric pain, with all subscores significantly reduced at 6 and 12 months of GES. The authors argue that the statistical significance of the results, which were also accompanied by a significant improvement in the HQOL (Heath-Related Quality of life) evaluated using the previously validated SF-36 questionnaire, might depend on the larger database available for analysis in their study [41]. They also emphasize that, although GES does not correct other comorbidities of underlying diabetes, clearly makes life more functional on both mental (MCS) and physical [PCS) levels for the majority of patients. The significant reduction in HbAlc levels combined with the reduction in days of hospital stay was their major finding. In fact, by controlling nausea and vomiting and thus stabilizing food intake and maximizing the glucose/insulin relation, better diabetes control was achieved. The absence of nausea and vomiting could allow those patients to be candidates for renal and pancreas transplantation in the future because they can absorb the oral immunosuppressant agents needed to prevent organ rejection. In addition, the economics of fewer hospitalizations and the accompanying substantial savings emphasize another parameter of long-term outcome and quality of life [42]. Despite all these positive aspects, the method has also some deficiencies: the median gastric retention measured by a standardized 4-h scintigraphy of a solid meal was not significantly reduced at 12 months, indicating no special association between changes in symptoms and GE. The fact that other papers reported a significantly improved GE with the majority of gastroparesis patients $(67 \%)$, getting back to normal levels and reversing gastric dysrhythmia with enhancement of the gastric slow waves [43], might depend on different stimulation parameters used. This suggests that in the future different stimulation parameters will be needed to reverse dysmotility in DGP. In Lin's study in patients with long-term diabetes
[44], the major adverse event related to GES therapy was postoperative infection, which often required the device to be removed. There was a significant relation between the risk of death and duration of diabetes $(P<0.02)$ : the mean duration of diabetes for the four patients who died in their study was 25.3 years, substantially higher than in the survivors (12 years) or those that deceased in another study discussed above [39]. Without taking into account open label studies, often claiming an impressive success rate, even as high as $97 \%$ improvement in more than $80 \%$ of patients [39], a randomized, double-blinded, multicenter clinical trial, later transformed into an unblinded cross-over trial (Worldwide Antivomiting Electrical Stimulation Study [WAVESS]) confirmed significant improvement in gastrointestinal symptoms. This study was limited to some extent as it recruited fewer patients than intended (33, when powered for 80) and only showed improvement in weekly vomiting frequency during the randomization phase [45]. Overall the various studies published during the last ten years or so did not use the same methods to quantify symptoms, so it is extremely difficult to draw sound undebatable conclusions. Moreover the Enterra settings in terms of frequency, energy and on/off periods were not always reported and in some cases success was claimed in nonresponders after adjustment of the frequency and energy delivered by the device. Thus it is difficult to draw straightforward conclusions on the overall efficacy of Enterra, especially as the mentors of this technique claim that in nonresponders (who usually have painful gastroparesis and make use of narcotics) good results may be obtained by adjusting voltage, frequency and on/off periods of stimulation [46]. Positive results have been undoubtedly obtained in the vast majority of cases reported in the literature.

In 2009 O'Grady, et al. tried to summarize the current evidence for the efficacy of high-frequency GES in the treatment of gastroparesis, by conducting a comprehensive literature review and a meta-analysis of selected published studies from January 1992 to August 2008. They included as sources Medline, EMBASE, Google Scholar, ISI Proceedings, the Cochrane Library, and online registers of controlled clinical trials on implanted high-frequency permanent GES devices and, because of the limited numbers of controlled clinical trials, took into account 13 noncontrolled observational studies. They excluded publications reporting duplicate outcomes from a previous study and small case series. Post-GES measures demonstrated a consistent and significant benefit over baseline measures for both vomiting severity score and nausea severity score; SF36 PCS and MCS Quality of Life measurement outcomes, which were available from four studies, demonstrated consistent and highly significant improvements post-GES compared with baseline values; moreover, prior to GES, against a total of 96 patients requiring enteral or parenteral nutritional support at baseline, only 21 still required it after GES.

On the other hand, the natural history of gastroparesis remains poorly understood [47], and even patients with longstanding disease may spontaneously improve with standard medical care alone. Another issue in relation to study design is the potential confounding effect of concurrent pharmacological therapy, in particular opiate use, which is present in some of the studies included in this meta- 
analysis. Opiates may cause complex gastric dysrhythmias, slow gastric emptying, and exacerbate gastroparesis-related symptoms: one study included reported that $45 \%$ of the patients were narcotic dependent prior to device implantation and were actively weaned, with variable success, after the institution of high-frequency GES [48]. Thus it possible that symptom improvement might have resulted from the reduction in narcotic dosage rather than the implementation of high-frequency GES. Moreover, the non-responders to GES may have had their devices removed, or may have declined to participate in post-treatment evaluations, leading to a greater representation of responders in the summary statistics. Meanwhile, research continues into other methods of gastric stimulation, and these also hold some promise for the treatment of gastroparesis as shown, for example, by multichannel gastric pacing accelerating gastric emptying in a canine model [49]. There is therefore need to improve the efficiency and protocol designs of such treatments before they become routine procedures.

A major consideration arises from McCallum report on 55 cases of diabetic GP treated wiuth Enterra undergoing a controlled, prospective, multicenter cross-over study [50]: the rapid and significant induction of symptom improvement in the first 6 weeks was sustained despite a period of up to 3 months with the device off. Therefore, the carryover effects of neuro-stimulation may persist and remain effective over a number of weeks to months, thus allowing the authors to hypothesize that the initial 6-week stimulation period rendered the subsequent double-blind data null.

A follow-up study with a different design has therefore to be suggested to address these other potential explanations for various studies' results and, in light of data suggesting the possibility of longterm carryover effects of the therapy, a cross-over design probably should be avoided. These results support the efficacy of Enterra therapy for severe diabetic gastroparesis patients failing medical therapy but also suggest that more research is needed to address the remaining questions about study results. In particular, the most meaningful design is a parallel study design with subjects randomized at the time of surgery to implant the Enterra device to either on or off for a 3- to 6-month time period. This would address previous study concerns.

\section{CONCLUSIONS}

Other mechanisms of action that could be hypothesized for high-frequency GES include gastric fundic relaxation, an action on the autonomic nervous system, and release of GI hormones, including ghrelin. Activation of central control mechanisms for nausea and vomiting in the brain stem and central nervous system by stimulating afferent pathways is the most unifying theory, but as yet there are no supporting data. GES might in fact increase vagal function, also resulting in increased fundic accommodation and possibly decreased sensitivity to distention [51]. Although these hypotheses might fit some of the observations, it is important to note that there is still no evidence that the vomiting center function is actually altered, and the relationship between the described changes and symptom relief requires more study. Most patients who respond to GES do so fairly soon after implantation of the device. This has led to the proposal that temporary endoscopic placement of stimulation leads in the stomach can be used to predict response to the permanent device. The choice of the current parameters used in GES was partly based on battery considerations. Better methods to detect the underlying electrical signal including mucosal EGG might clarify the role of EGG as well as predict response to GES.

According to some authors, the fact that Enterra Therapy provides a modicum of relief to this group of patients who are at the 'end of their rope' is an argument in favor of its effectiveness [45]. Clearly, even with gastric neurostimulation some patients will continue to live with crippling symptoms. Enterra Therapy is not meant to be a substitute for other treatments - patients may still require antiemetics, pain medication, anxiolytics and antidepressants, as well as dietary support, possibly with jejunal enteral feedings and psychosocial support. Patients require constant follow-up. Any physiological or psychological stress may cause recurrent symptoms, and bridging the patient through these periods requires knowledge of inciting factors and their interventions. However, the pros and cons need to be viewed in terms of the present disease burden and the lack of effective treatments (Tables 1 and 2). Additionally, there are other types of gastric neurostimulation, with placement of electrodes endoscopically or via a gastrostomy. These techniques may hold promise. In fact, there are a few studies available aiming to improve the technique of gastric neurostimulation and there still seems to be a need for randomized double blinded controlled clinical trials. These will be helpful in elucidating properly the contribution of confounding factors to the gastroparesis puzzle.

Table 1. Main PROS of GES

\begin{tabular}{|l|}
\hline (Near) normalization of stomach motility \\
\hline good gastric emptying of liquids \\
\hline vomiting rate decrease \\
\hline relief of nausea, early satiety, bloating, postprandial fullness \\
\hline early improvement (by 6 weeks) with sustained effect \\
\hline improved quality of life \\
\hline improved nutrition \\
\hline reduction in HbA1c levels \\
\hline decrease in hospitalization days \\
\hline
\end{tabular}

Table 2. Main CONS of GES

\begin{tabular}{|l|}
\hline uncertain patient selection criteria \\
\hline poor definition of optimal electrode position \\
\hline need to define best on/off periodicity \\
\hline unknown optimal stimulation parameters \\
\hline partial emptying of solids \\
\hline some persistence of vomiting \\
\hline possible infections causing device removal / death (rare) \\
\hline poor understanding of the natural history of gastroparesis \\
\hline Potential confounding effect of concurrent pharmacological therapy \\
\hline
\end{tabular}




\section{DISCLOSURE}

This paper was solicited by the interest of the authors in this field. There is no conflict of interests to declare.

\section{ABBREVIATIONS}

$\begin{array}{ll}\mathrm{AGA} & =\text { American Gastroenterological Association } \\ \mathrm{FDA} & =\text { Food and Drug Administration } \\ \mathrm{GI} & =\text { Gastrointestinal } \\ \mathrm{GES} & =\text { Gastric Electric Stimulation } \\ \mathrm{KUMC} & =\text { Kansas Medical Center } \\ \mathrm{HRQL} & =\text { Health-Related Quality of Life } \\ \text { REFERENCES }\end{array}$

[1] Loo FD, Palmer W, Soergel KH, Kalbfleish JH, Wood CM. Gastric emptying in patients with diabetes mellitus. Gastroenterology 1984; 194(86): 485-94.

[2] Vaisman N, Weintrob N, Blumental A, Yosefsberg Z, Vardi P. Gastric emptying in patients with type 1 diabetes mellitus. Ann NY Acad Sci 1999; 873: 506-11.

[3] Annese V, Bassotti G, Caruso N, et al. Gastrointestinal motor dysfunction, symptoms and neuropathy in non insulin dependent (type 2) diabetes mellitus. J Clin Gastroenterol 1999; (29): 171-7.

[4] Kong MF, Horowitz M, Jones KL, Wisharth JM, Harding PE. Natural history of diabetic gastroparesis. Diabetes Care 1999; 22: 503-7.

[5] Leiter LA, Yale J-F, Chisson JL, Harris SB, Kleinstiver P, Sauriol P. Assessment of the impact of fear of hypoglycemic episodes on glycemic and hypoglycemia management. Can J Diabetes 2005; 29(3): 186-92 .

[6] Davis SN. Mann S, Briscoe VJ, Ertl AC, Tate DB. Effects of intensive therapy and antecedent hypoglycemia on counterregulatory responses to hypoglycemia in type 2 diabetes. Diabetes 2009; 58(3): 701-9.

[7] The DCCT Investigators group. Hypoglycemia in the diabetes control and complications trial. The diabetes control and complications trial research group. Diabetes 1997; 46(2): 271-86.

[8] Hyett B, Martinez FJ, Brian MG, et al. Delayed radionucleotide gastric emptying studies predict morbidity in diabetics with symptoms of gastroparesis. Gastroenterology 2009; 137(2): 724-5.

[9] Sampson MJ, Wilson S, Karagiannis P, Edmonds M, Watkins PJ. Progression of diabetic autonomic neuropathy over a decade of insulin dependent diabetics. QJM 1990; (75): 635-46.

[10] Verne GN, Sninsky GA. Diabetes and the gastrointestinal tract. Gastroenterol Clin North Am 1998 (27): 861-74.

[11] Lyrenas EB, Olsson EHK, Arvidsson UC, Orn TJ, Spjuth JH. Prevalence and determinants of solid and liquid gastric emptying in unstable type 1 diabetes. Diabetes Care 1997; (20): 413-6.

[12] Troncon LE, Rosa-e-Silva L, Olivera RB, Iazigi N, Gallo L Jr, Foss MC. Abnormal intragastric distribution of a liquid nutrient meal in patients with diabetes mellitus. Dig Dis Sci 1998; 43: 1421-9.

[13] Horowitz M, Maddox AF, Wishart JM, Harding PE, Chatterton BE, Shearman DJ. Relationship between esophageal transit and liquid gastric emptying in diabetes mellitus. Eur J Nucl Med 1991; (18): 229-34.

[14] Wright RA, Clemente R, Wathen R. Diabetic gastroparesis: an abnormality of gastric emptying of solids. Am J Med Sci 1985; 289: $240-2$.

[15] Urbain JL, Vekemans MC, Bouillon R, et al. Characterization of gastric antral motility disturbances in diabetes using a scintigraphic technique. J Nucl Med 1993; 34: 576-81.

[16] Oster-Jogersen E, Pedersen SA, Larsen ML. The influence of induced hyperglycemia on gastric emptying rate in healthy humans. Scand J Clin Lab Invest 1990; 50: 831-6.

[17] Schvarcz E, Palmér M, Aman J, Horowitz M, Stridsberg M, Berne C. Physiological hyperglycemia slows gastric emptying in normal subjects and patients with insulin dependent diabetes mellitus. Gastroenterology 1997; (113): 60-6.

[18] Fraser RJ, Horowitz M, Maddox AF, Harding PE, Chatterton BE, Dent J. Hyperglycemia slows gastric emptying in type 1 (insulin dependent) diabeted mellitus. Diabetologia 1990; 33: 675-80.
[19] Schvarcz E, Palmér M, Aman J, Lindkvist B, Beckman KW. Hypoglycemia increases the gastric emptying rate in patients with Type 1 diabetes mellitus. Diabet Med 1993; 10: 660-3.

[20] Holzäpfel A, Festa A, Stacher-Janotta G, et al. Gastric emptying in non insulin dependent diabetes before and after therapy readjustment: no influence of actual blood glucose level. Diabetologia 1999; 42: 1410-2.

[21] Nowak TV, Johnson CP, Kalbfleisch JH, et al. Highly variable gastric emptying in patients with insulin dependent diabetes mellitus. Gut 1994; 37: 23-9.

[22] Duchen LW, Anjorin A, Watkins PJ, Mackay JD. Pathology of autonomic neuropathy in diabetes mellitus. Ann Intern Med 1980; 92: 301-3.

[23] Yoshida MM, Schuffler MD, Sumi SM. There are no morphologic abnormalities of the gastric wall or abdominal vagus in patients with diabetic gastroparesis. Gastroenterology 1988; 94: 907-14.

[24] Spallone V. Glycaemic control and gastric emptying. Diabetes Nutr Metab 2004; 17(1): 47-55.

[25] Camilleri MG. Clinical practice. Diabetic gastroparesis. N Engl J Med 2007; 356(8): 820-9.

[26] Abrahamsson H. Treatment options for patients with severe gastroparesis. Gut 2007; 56(6): 877-83.

[27] Patrick A, Epstein O. Review article: gastroparesis. Aliment Pharmacol Ther 2008; 27(9): 724-40.

[28] Parkman HP, Hasler WL, Fisher RS. American gastroenterology association technical review on the diagnosis and treatment of gastroparesis. Gastroenterol 2004; 127(5): 1592-622.

[29] Sloots CE, Rykx A, Cools M, Kerstens R, De Pauw M. Efficacy and safety of prucalopride in patients with chronic noncancer pain suffering from opioid-induced constipation. Dig Dis Sci 2010; 55(10): 2912-21.

[30] Camilleri M. Clinical practice diabetic gastroparesis. N Engl J Med 2007; 356(8): 820-9.

[31] Abrahamsson H. Treatment options for patients with severe gastroparesis. Gut 2007; 56(6): 877-83.

[32] Abell TL, Camilleri M, Donohoe K, et al. Consensus recommendations for gastric emptying scintigraphy: a joint report of the American neurogastroenterology and motility society and the society of nuclear medicine. Am J Gastroenterol 2008; 103(3): 75363 .

[33] Abell T, Lou J, Tabbaa M, Batista O, Malinowski S, Al-Juburi A. Gastric electric stimulation for gastroparesis improves nutritional parameters at short, intermediate, and long-term followup. JPEN J Parenter Enteral Nutr 2003; 27: 277-81.

[34] Jones MP, Ebert CC, Murayama K. Enterra for gastroparesis (letter). Am J Gastroenterol 2003; 98: 2578

[35] American gastroenterological association technical review on the diagnosis and treatment of gastroparesis. Gastroenterol 2004; 127 : 1592-622.

[36] Lin Z, Forster J, Sarosiek I, McCallum RW. Treatment of diabetic gastroparesis by high-frequency gastric electrical stimulation. Diabetes Care 2004; 27: 1071-6.

[37] Voeller G, Salem A, Gabor O. Electrical stimulation at a frequency higher than basal rate in human stomach. Dig Dis Sci 1997; 42: 885-91.

[38] Forster J, Sarosiek I, Delcore R, Lin ZY, Raju GS, McCallum RW. Gastric pacing is a new surgical treatment for gastroparesis. Am J Surg 2001; 182: 676-81.

[39] Abell TL, Van Cutsemb E, Abrahamsso H. Gastric electrical stimulation in intractable symptomatic gastroparesis. Digestion 2002; 66: 204-12.

[40] Abell T, Mccallum R, Hocking M, et al. Gastric electrical stimulation for medically refractory gastroparesis. Gastroenterology 2003; $125: 421-8$.

[41] Ware JE Jr. SF-36 Health survey, manual and interpretation guide. Boston, MA, Health Institute, New England Medical Center 1993.

[42] McCallum RW, George SJ. Gastroparesis (Review). Clin Perspect Gastroenterol 2001; 4: 147-54.

[43] McCallum RW, Chen JDZ, Zihiue L, Bruce DS, Williams RD, Ross RA. Gastric pacing improves emptying and symptoms in patients with gastroparesis. Gastroenterology 1998; 114: 456-61.

[44] Hickman MS, Schwesinger WH, Page CP. Acute cholecystitis in the diabetic: a casecontrol study of outcome. Arch Surg 1998; 123: 409-11.

[45] O'Grady G, Egbuji JU, Du P, Cheng LK, Pullan LJ, Windsor JA High-frequency gastric electrical stimulation for the treatment of 
gastroparesis: a meta-analysis. World J Surg 2009; 33(8): 1693701.

[46] Abidi N, Starkebaum WL, Abell TL. An energy algorithm improves symptoms in some patients with gastroparesis and treated with gastric electrical stimulation. Neurogastroenterol Motil 2006; 18(4): 334-8.

[47] Vittal H, Farrugia G, Gomez G, Pasricha PJ. Mechanisms of disease: the pathological basis of gastroparesis - a review of experimental and clinical studies. Nat Clin Pract Gastroenterol Hepatol 2007; 4: 336-46.

[48] Mason RJ, Lipham J, Eckerling G, et al. Gastric electrical stimulation: an alternative surgical therapy for patients with gastroparesis. Arch Surg 2005; 140: 841-6; discussion 847-8.
[49]

Chen JD, Xu X, Zhang J, et al. Efficiency and efficacy of multichannel gastric electrical stimulation. Neurogastroenterol Motil 2005; 17: 878-82.

[50] McCallum RW, Snape W, Brody F, Wo J, Parkman HP, Nowak T. Gastric electrical stimulation with enterra therapy improves symptoms from diabetic gastroparesis in a prospective study. Clin Gastroenterol Hepatol 2010; 8: 947-54.

[51] Camilleri M, Papathanasopoulos A, Odunsi ST. Actions and therapeutic pathways of ghrelin for gastrointestinal disorders. Nat Rev Gastroenterol Hepatol 2009; 6(6): 343-52.

(C) Tatti et al.; Licensee Bentham Open.

This is an open access article licensed under the terms of the Creative Commons Attribution Non-Commercial License (http://creativecommons.org/licenses/by$\mathrm{nc} / 3.0 /$ ) which permits unrestricted, non-commercial use, distribution and reproduction in any medium, provided the work is properly cited. 